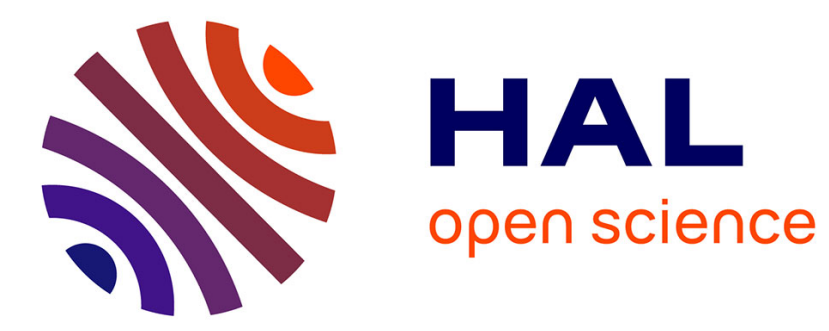

\title{
Dislocation Mechanics Based analysis of Material Dynamics Behavior : Enhanced Ductility, Deformation Twinning, Shock Deformation, Shear Instability, Dynamic Recovery
}

F. Zerilli, R. Armstrong

\section{To cite this version:}

F. Zerilli, R. Armstrong. Dislocation Mechanics Based analysis of Material Dynamics Behavior: Enhanced Ductility, Deformation Twinning, Shock Deformation, Shear Instability, Dynamic Recovery. Journal de Physique IV Proceedings, 1997, 07 (C3), pp.C3-637-C3-642. 10.1051/jp4:19973109 jpa00255393

\section{HAL Id: jpa-00255393 \\ https://hal.science/jpa-00255393}

Submitted on 1 Jan 1997

HAL is a multi-disciplinary open access archive for the deposit and dissemination of scientific research documents, whether they are published or not. The documents may come from teaching and research institutions in France or abroad, or from public or private research centers.
L'archive ouverte pluridisciplinaire HAL, est destinée au dépôt et à la diffusion de documents scientifiques de niveau recherche, publiés ou non, émanant des établissements d'enseignement et de recherche français ou étrangers, des laboratoires publics ou privés. 


\title{
Dislocation Mechanics Based analysis of Material Dynamics Behavior: Enhanced Ductility, Deformation Twinning, Shock Deformation, Shear Instability, Dynamic Recovery
}

\author{
F.J. Zerilli ${ }^{(1)}$ and R.W. Armstrong* \\ Naval Surface Warfare Center, Indian Head Division, 101 Strauss Avenue, \\ Indian Head 20640-5035, U.S.A. \\ * University of Maryland, College Park 20742, U.S.A.
}

\begin{abstract}
Further developments are described for the dislocation mechanics based constitutive equation analysis previously used to describe the separate dynamic stress-strain behavior of fcc and bcc metal polycrystals. An enhanced hardening and ductility in copper and certain tantalum materials at higher strain rates in split Hopkinson pressure bar tests and in shock loading are attributed to enhanced dislocation generation rather than to dislocation drag. Added material strengthening is accounted for also by deformation twinning in ARMCO iron and titanium and in shocked copper and tantalum. The separate equations are applied to calculate the critical strain for shear banding in copper, iron, and the titanium alloy, Ti-6Al-4V. In the two latter cases, the results are very sensitive to the details of the strain-hardening behavior and the need is demonstrated for a dynamic recovery factor to account for the onset of shear banding. Consideration is given also to the possibility that shear band behavior requires explanation on a more fundamental Hall-Petch dislocation pile-up basis.
\end{abstract}

\section{INTRODUCTION}

At the DYMAT Conference in 1988, a simple dislocation mechanics formulation for constitutive equations for metals based on the idea of thermally activated motion of dislocations was described [1]. Separate relations were given for face-centered-cubic (fcc) and body-centered-cubic (bcc) metals based upon the nature of the dislocation interactions [2]. For bcc metals, the motion of dislocations is governed predominantly by the interaction with the overall lattice potential (the Peierls-Nabarro stress) which leads to essentially temperature and strain-rate independent strain hardening. For fcc metals, the predominant interaction is produced by dislocation intersections, leading to temperature and strain-rate dependent strain hardening. Hexagonal-close-packed (hcp) metals have a stress-strain behavior falling somewhere between bcc and fcc metals.

Recently [3], in order to describe the intermediate behavior of hcp materials and certain alloy steels, both Peierls stress type interactions (predominant in bcc) and intersection-of-forest-dislocations type interactions (predominant in $\mathrm{fcc}$ ) were introduced into a single equation written in the form

$$
\sigma=\sigma_{a}+B e^{-\beta T}+B_{0} \sqrt{\epsilon} e^{-\alpha T}
$$

where

$$
\beta=\beta_{0}-\beta_{1} \ln \dot{\epsilon}
$$

${ }^{(1)}$ Supported by NSWC Independent Research Funds 


$$
\alpha=\alpha_{0}-\alpha_{1} \ln \dot{\epsilon},
$$

and

$$
\sigma_{a}=\sigma_{G}+k \ell^{-1 / 2} \text {. }
$$

In Eq. (1), $\sigma$ is the Mises equivalent stress, $\epsilon$ is the Mises equivalent strain, $\dot{\epsilon}$ is the strain rate, $\mathrm{T}$ is the absolute temperature, $\ell$ is the average grain diameter, and $\sigma_{\mathrm{G}}$ is a constant athermal stress due to the effect of solutes and initial dislocation density. The quantities $\mathrm{B}, \beta_{0}, \beta_{1}, \mathrm{~B}_{0}, \alpha_{0}$, and $\alpha_{1}$ are constants related to the thermally activated dislocation interactions while $k$ is the microstructural stress intensity for overcoming the resistance to deformation at grain boundaries. The first term in Eq. (1), $\sigma_{\mathrm{a}}$, is an athermal component of the flow stress determined mainly by the effect of solutes and grain boundaries. The second term arises from a thermal activation analysis of the Peierls stress interactions, and the third term arises from a thermal activation analysis for the overcoming of dislocation intersections that is associated with the strain hardening behavior of the material. The dependence of the flow stress on $\sqrt{\epsilon}$ follows from Taylor's calculation of the maximum average stress which will allow a lattice of positive and negative edge dislocations to remain in stable equilibrium [4].

The consequences of Eqs. (1 -4) and their predecessor separate equations are explored in the following sections as applied to enhanced ductility effects in copper and tantalum, deformation twinning in iron, titanium, copper, and tantalum, and susceptibility to shear instabilities in copper, iron, and titanium alloy Ti-6Al-4V.

\section{ENHANCED DUCTILITY IN COPPER AND TANTALUM}

Zerilli and Armstrong [5] noted that a dislocation drag explanation of the strong upturn in flow stress of copper at strain rates above $10^{3}-10^{4} \mathrm{~s}^{-1}$ in split Hopkinson bar tests required a corresponding reduction in the material ductility. This is illustrated for copper in Fig. 1 wherein uniform strain data of Regazzoni and Montheillet [6] are compared to calculations in which the drag coefficient is placed in the range sufficient to reproduce the observed enhancement of the flow stress. Tantalum shows a similar behavior [7]. Application of Eq. (1) to the calculation of the uniform strain from recent tantalum results of Chen and Gray [8] showed enhanced ductility at high strain rates [9]. Most recently, Frutschy and Clifton have reported strongly increased strain hardening behavior for copper at strain rates of the order of $10^{6} \mathrm{~s}^{-1}[10]$.

\section{DEFORMATION TWINNING}

The dependence of the twinning stress on grain size is similar to the dependence of the athermal part of the flow stress on grain size (cf. Eq. 4) and may be written [11]

$$
\sigma_{T}=\sigma_{T 0}+k_{T} \ell^{-1 / 2}
$$

where, for iron, $\sigma_{\mathrm{T} 0}$ is $330 \mathrm{MPa}$ and $k_{\mathrm{T}}$ is $2.8 \mathrm{MPa}-\mathrm{m}^{1 / 2}$. Twinning occurs at a flow stress level of 600 $\mathrm{MPa}$ for iron with a grain size of 100 microns. This stress will be achieved in impacts of $200 \mathrm{~ms}^{-1}$ in which strain rates of $10^{4} \mathrm{~s}^{-1}$ are generated. Twinning has been shown to occur in fcc metals, but generally 
at very much higher stress levels. For copper, the stress levels are in the range of 1600 to $2800 \mathrm{MPa}$ that are reached in shocks [12].

With a constitutive model for twinning based on the idea that enough twinning will occur in a grain to accommodate the excess by which the Mises effective stress exceeds the twinning threshold stress, numerical simulations of Taylor cylinder impacts produced good agreement with experimental results for iron, titanium, and zirconium [13]. Iron and titanium results are shown in Figs. 2 and 3. The twin based strengthening is accounted for on a Hall-Petch type grain size refinement basis. The results indicate that twinning hardens these metals by effectively reducing the material grain size and the microstructure within the grains.

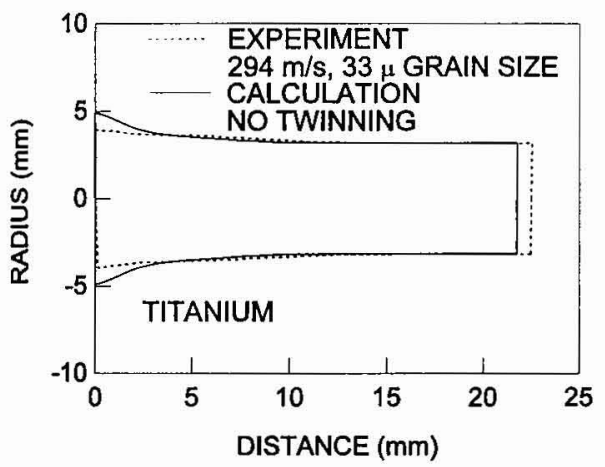

Figure 3a: Poor result for titanium when twinning not accounted for.

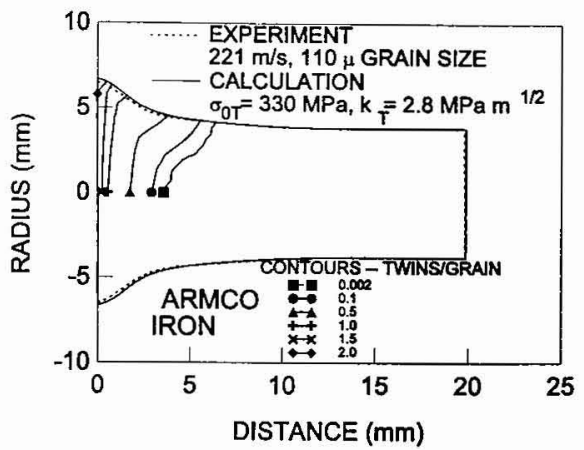

Figure 2: ARMCO iron Taylor cylinder, $221 \mathrm{~m} / \mathrm{s}$ impact velocity, with twinning model.

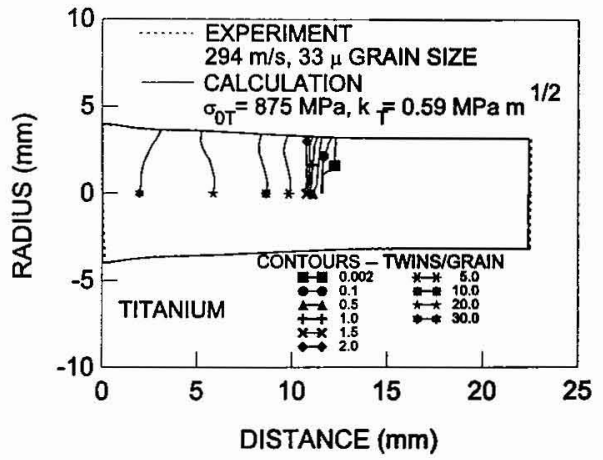

Figure 3b: Excellent result for titanium with new twinning model when twinning parameters determined at impact velocity of $294 \mathrm{~m} / \mathrm{s}$.

In describing the twinning model, there are two cases to consider, $\sigma_{\mathrm{VM}}<\sigma_{\mathrm{f}}$ (elastic deformation), and $\sigma_{\mathrm{VM}}=\sigma_{\mathrm{f}}$ (plastic deformation) where the flow stress is given by

$$
\sigma_{f}=\sigma_{0}+k l^{-1 / 2}
$$

and

$$
\sigma_{0}=\sigma_{G}+B e^{-\beta T}+K \epsilon^{n} .
$$

In the elastic case, if $\sigma_{\mathrm{VM}}>\sigma_{\mathrm{T}}$, we calculate a new effective grain size by setting $\sigma_{\mathrm{T} 0}+\mathrm{k}_{\mathrm{T}} \mathrm{e}^{-12}=\sigma_{\mathrm{VM}}$, giving

$$
\ell=\left(\frac{k_{T}}{\sigma_{V M}{ }^{-\sigma_{0 r}}}\right)^{2} .
$$

In the plastic case, if $\sigma_{\mathrm{f}}>\sigma_{\mathrm{T}}$, the new effective grain size (for raising $\sigma_{\mathrm{T}}$ to $\sigma_{\mathrm{f}}$ ) is given by

$$
\ell=\left(\frac{k_{T}-k}{\sigma_{0}-\sigma_{O T}}\right)^{2} .
$$

Support for this type of twin based strengthening is provided by results reported by Meyers, et al., [14] who found that twinning in large grain size copper shock hardens the material to an extent that can be explained on a Hall-Petch grain-size refinement basis and concomitantly reduces the strain hardening, 
thereby increasing the susceptibility to shear instability. In small grain size material, no twinning was observed, little or no initial shock hardening occurred, but increased strain hardening was observed with a concomitant decrease in susceptibility to shear instability (enhanced ductility). Murr, et al., [15] observed profuse twinning in shock deformed tantalum, again sufficient to explain the shock hardening on the HallPetch grain size refinement basis.

\section{THERMOPLASTIC SHEAR INSTABILITY}

The criterion for the development of localized large shear deformations is determined by the stability of the solutions to the equations of motion when small perturbations are applied. Bai [16] has shown that small perturbations will grow exponentially with time if

$$
\frac{-\tau_{0}\left(\frac{\partial \tau}{\partial T}\right)_{0}}{\rho_{0} c_{v}\left(\frac{\partial \tau}{\partial \gamma}\right)_{0}} \geq 1+\sqrt{\frac{4 \kappa \dot{\gamma}_{0}\left(\frac{\partial \tau}{\partial T}\right)_{0}}{\rho_{0} c_{v}^{2}\left(\frac{\partial \tau}{\partial \gamma}\right)_{0}}}
$$

where the subscript 0 indicates the quantity refers to the uniform base solution of the simple shear equations and $\rho_{0}$ is the initial density (assumed constant), $\gamma$ is the shear strain, $\tau$ is the shear stress, $\kappa$ is the thermal conductivity, and $c_{\mathrm{v}}$ is the heat capacity at

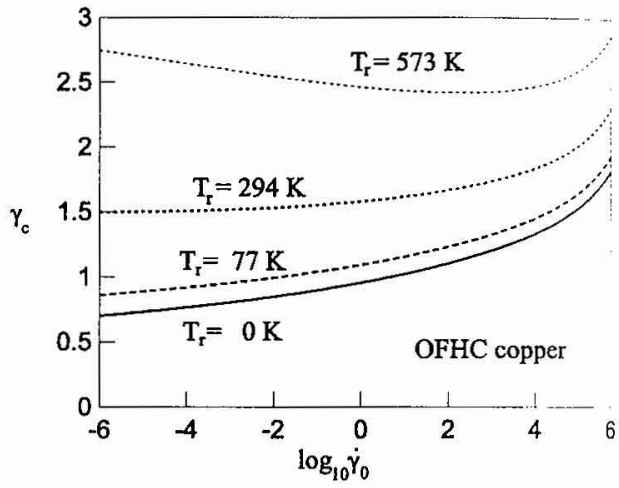

Figure 4: Critical strain for adiabatic shear instability to develop in fcc OFHC copper. Curves are plotted vs. strain rate for several initial temperatures, $T_{\mathrm{r}}$. constant volume (assumed constant). The term under the square root on the right hand side of Eq. (10) vanishes when the thermal conductivity is zero and, in any case, is very small for a typical metal. Thus Eq. (10) amounts to the adiabatic condition proposed by Zener and Hollomon [17] in 1944 -- the shear instability develops when the rate of thermal softening overcomes the rate of work hardening.

The critical strain vs. strain rate for the development of the shear instability in the fcc metal, OFHC copper, calculated from Bai's criterion, is shown in Fig. 4. The constitutive equation for $\mathrm{OFHC}$ copper is the fcc equation in terms of shear stress and shear strain:

$$
\tau=c_{0}+B_{0} \sqrt{\gamma} e^{-\beta T}
$$

where

$$
\beta=\beta_{0}-\beta_{1} \ln \dot{\gamma}
$$

The critical strain vs. strain rate for development of the shear instability in the bcc metal, ARMCO iron, using Bai's criterion, is shown in Fig. 5. In this case, the constitutive equation for ARMCO iron is the bcc equation:

$$
\tau=c_{0}+B_{0} e^{-\beta T}+K \gamma^{n} .
$$

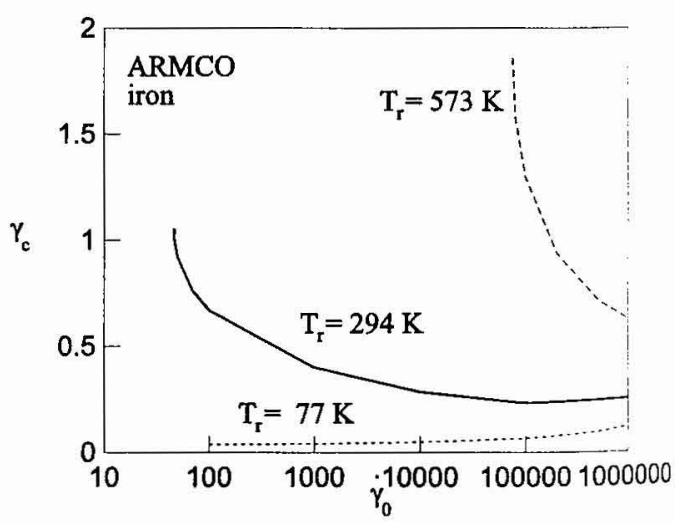

Figure 5: Critical strain for adiabatic shear instability to develop in bcc ARMCO iron. Curves are plotted vs. strain rate for several initial temperatures, $T_{r}$.

The two figures illustrate the general features of shear banding in fcc and bcc metals which were predicted earlier by analysis both of the tensile plastic instability and dislocation pile-up stress concentrations [18]. The bcc metals are typically more susceptible to the shear instability, as shown by the smaller critical 
strains. The susceptibility increases with increasing strain rate in the bcc case and decreases with increasing strain rate in the fcc case, although these trends are reversed at the lowest initial temperatures in the bcc case and at the highest initial temperatures in the fcc case. Increasing initial temperature, of course, always tends to suppress the shear instability.

Critical strains for shear instability in Ti-6Al-4V were computed using the bcc constitutive equation which gives a close representation of experimental stress-strain data reported by Ogawa and Nojima [19], as shown in Fig. 6 [20], and found to be unreasonably large. It was found necessary to take into account the reduction of the strain hardening due to dynamic recovery in order to obtain reasonable results. When dynamic recovery is taken into account, Eq. (1) becomes

$$
\sigma=\sigma_{a}+B e^{-\beta T}+B_{0} \sqrt{\varepsilon_{r}\left(1-e^{-\varepsilon / t_{r}}\right)} e^{-\alpha T}
$$

where $\varepsilon_{\mathrm{r}}$ is a characteristic strain for recovery (the inverse of the probability for mobilizing an immobilized dislocation) [21]. A value of the recovery strain $\varepsilon_{\mathrm{r}}$ of 0.5 is consistent with small strain data for the alloy and was chosen for the calculations presented here in Fig. 7. The results indicate that this alloy is more susceptible to shear banding than iron, as expected. However, the values of the critical strain are very sensitive to the value chosen for the recovery strain.

Consideration must also be given to the possibility that shear band behavior requires explanation on a more fundamental Hall-Petch dislocation pile-up basis. Armstrong, et al., [22] estimated the temperature rise that could be produced by dissipation of the energy in a dislocation pile-up when catastrophically released during fracturing as

$$
\Delta T \leq\left(k_{s} \ell^{1 / 2} / 16 \pi \kappa\right) \ln \left(2 K / c_{v} v b\right)
$$

where $\mathrm{v}$ is the dislocation velocity, $b$ is the Burgers vector, $\ell$ is a characteristic grain diameter, and $k_{s}$ is the theoretical shear stress intensity for fracturing

$$
k_{s}=\pi G b^{1 / 2}(2-v) / 8(1-v)
$$

where $G$ is the shear modulus and $v$ is Poisson's ratio. The dislocation pile-up/avalanche provides the thermal fluctuation to trigger the localized shear instability. The ratio of $k_{s}$ to $\kappa$ provides a criterion for susceptibility to shear banding. On this basis, Ti$6 \mathrm{Al}-4 \mathrm{~V}$ is very shear band susceptible, followed by iron, with copper being very low in susceptibility. This is consistent with the data reported by Ogawa and Nojima shown in Fig. 6, in which a significant influence of adiabatic heating on reduction of strain hardening is seen to occur for Ti-6Al-4V alloy.

\section{Acknowledgments}

This work was supported at NSWC by the Independent Research Program and at the University of Maryland by the Office of Naval Research.

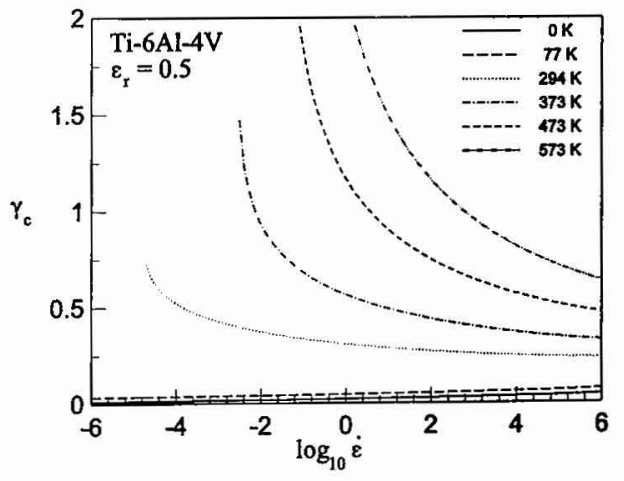

Figure 7: Critical strain for adiabatic shear instability to develop in hcp Ti-6Al-4V. Curves are plotted vs. strain rate for several initial temperatures. 


\section{References}

[1] Armstrong, R. W., and Zerilli, F. J., DYMAT 88, J. de Phys.-Coll. C3, 49 (1988) 529.

[2] Zerilli, F. J., and Armstrong, R. W., J. Appl. Phys. 61 (1987) 1816; ibid. 68 (1990) 1580.

[3] Zerilli, F. J., and Armstrong, R. W., in High Strain Rate Effects on Polymer, Metal and Ceramic Matrix Composites and Other Advanced Materials, edited by Y. D. S. Rajapakse and J. R. Vinson, AD-Vol. 48, The American Society of Mechanical Engineers, New York, 1995, pp. 121-126.

[4] Taylor, G. I., "The Mechanism of Plastic Deformation of Crystals", Proc. Roy. Soc. A145 (1934) 362.

[5] Zerilli, F. J., and Armstrong, R. W., Acta metall. mater. 40 (1992) 1803.

[6] Regazzoni, G., and Montheillet, F., in Mechanical Properties at High Rates of Strain, 1984, edited by J. Harding (The Institute of Physics Conference Series No. 70, 1984) pp. 63-70.

[7] Follansbee, P. S., Regazzoni, G., and Kocks, U. F., in Mechanical Properties at High Rates of Strain, 1984, edited by J. Harding (The Institute of Physics Conference Series No. 70, 1984) pp. 71-80.

[8] Chen, R. S., and Gray, III, G. T., in Tantalum Symposium, 1996, edited by E. S. Chen and A. W. Crowson (Minerals, Metals and Materials Society, Warrendale, PA, 1997), in print.

[9] Armstrong, R. W., Zhang, X. J., Feng, C., Williams, J. D., and Zerilli, F. J., in Tantalum Symposium. 1996, edited by E. S. Chen and A. W. Crowson (Minerals, Metals and Materials Society, Warrendale. PA, 1997), in print.

[10] Frutschy, K. J., and Clifton, R. J., in U. S. Army Solid Mechanics Symposium, Myrtle Beach, SC, 1996, in print.

[11] Armstrong, R. W., and Worthington, P. J., in Metallurgical Effects at High Strain Rates (Plenum, New York, 1974), p. $401 \mathrm{ff}$.

[12] Leslie, W. C., in Metallurgical Effects at High Strain Rates, edited by R. W. Rohde, B. M. Butcher. J. R. Holland, and C. H. Karnes (Plenum, New York, 1974), p. 571; de Andrade, U. R., Ph.D. Thesis, University of California, San Diego, 1993.

[13] Zerilli, F. J., and Armstrong, R. W., in Grain Size and Mechanical Properties -- Fundamentals and Applications, edited by M. A. Otooni, R. W. Armstrong, N. J. Grant, and K. Ishizaki (Materials Research Society, Pittsburgh, PA, 1995), p. 149ff.

[14] Meyers, M. A., Andrade, U. R., and Chokshi, A. H., "The Effect of Grain Size on the High-Strain, High-Strain-Rate Behavior of Copper", Met. and Mat. Trans. A, 26A (1995) 2881.

[15] Murr, L. E., Meyers, M. A., Niou, C-S., Chen, Y. J., Pappu, S., and Kennedy, C., "Shock-Induced Deformation Twinning in Tantalum", Acta mater. 45 (1997) 157.

[16] Bai, Y. L., "Thermo-Plastic Instability in Simple Shear", J. Mech. Phys. Solids 30 (1982) 195-207.

[17] Zener, C., and Hollomon, J. H., J. Appl. Phys. 15 (1944) 22.

[18] Armstrong, R. W., and Zerilli, F. J., "Dislocation Mechanics Aspects of Plastic Instability and Shear Banding", Mech. Mater. 17 (1994) 319.

[19] Ogawa, K., and Nojima, T., "Impact Strength of Titanium Alloys", J. Soc. Mater. Sci. JPN37 (1988) p. $41 \mathrm{ff}$.

[20] Zerilli, F. J., and Armstrong, R. W., in Shock Compression of Condensed Matter -- 1995, edited by S. C. Schmidt and W. C. Tao, AIP Conference Proceedings 370 (American Institute of Physics, New York, 1996) p. 315ff.

[21] Zerilli, F. J., and Armstrong, R. W., article in preparation.

[22] Armstrong, R. W., Coffey, C. S., and Elban, W. L., "Adiabatic Heating at a Dislocation Pile-up Avalanche", Acta metall. 30 (1982) 2111. 